Letter to the Editor

\title{
Are current ophthalmology clinical practices relating to blue light-filtering intraocular lenses evidence-based?
}

\author{
Sumeer Singh MPhil, ${ }^{1}$ Andrew J Anderson PhD, ${ }^{1}$ Stephanie L Watson FRANZCO PhD ${ }^{2}$ \\ and Laura E Downie PhD ${ }^{1}$
}

\begin{abstract}
${ }^{1}$ Department of Optometry and Vision Sciences, The University of Melbourne, Victoria, Australia; ${ }^{2} T$ he University of Sydney, Save Sight Institute, Discipline of Ophthalmology, Sydney Medical School, Sydney, New South Wales, Australia.
\end{abstract}

Correspondence: Dr Laura E Downie, Senior Lecturer, Department of Optometry and Vision Sciences, The University of Melbourne, Parkville VIC Australia 3010 Email: Idownie@unimelb.edu.au

Received 17 September 2019; accepted 29 September 2019 Funding sources / Financial disclosure: There was no specific funding for this study. S Watson is a Sydney Medical School Foundation Fellow.

Conflict of interest: None

This is the author manuscript accepted for publication and has undergone full peer review but has not been through the copyediting, typesetting, pagination and proofreading process, which may lead to differences between this version and the Version of Record. Please cite this article as doi: 10.1111/ceo.13653

This article is protected by copyright. All rights reserved. 
Cataract surgery, with intraocular lens (IOL) implantation, is a common surgical procedure. Current types of IOLs include those that filter ultraviolet (UV) only, or UV and blue light. Although protracted exposure to high-intensity blue light leads to retinal damage under experimental conditions, ${ }^{1,2}$ a recent systematic review found a lack of clinical evidence to support using blue light-filtering IOLs for preserving macular health or altering the long-term risks of age-related macular degeneration (AMD). ${ }^{3}$ Furthermore, clinicians have been urged to be mindful of this lack of evidence when considering implantation of blue light-filtering IOLs. ${ }^{4}$ However, to date, no research has investigated ophthalmologists' knowledge, attitudes or clinical practice patterns in relation to these devices; we sought to examine these factors. This study, undertaken between May 2018 and February 2019, involved Australian ophthalmologists completing an anonymous, online questionnaire, adapted from a previous study 5 to approximately align with the current study population. The questionnaire consisted of the following sections: (i) Practitioner demographics and practice modality; (ii) Knowledge of blue light and its potential ocular effects; (iii) Frequency and prescribing of blue light-filtering IOLs; and (iv) Perceptions of the evidence for blue light-blocking IOLs. Approval was granted by the University of Melbourne Human Research Ethics Committee (\#1851566).

Completed responses were received from 72 ophthalmologists, hereafter referred to as the respondents, representing $\sim 9 \%$ of all Australian ophthalmologists. Table 1 summarises the respondent demographics. Four in five respondents correctly identified the wavelength range of blue light (400-500nm). A similar proportion did not consider blue light to cause retinal damage. In terms of sources considered to emit clinically important levels of blue light, most (80\%) respondents nominated the sun, and almost half selected mobile phones (Figure 1a).

The majority ( $88 \%$ ) of practitioners performed cataract surgery, hereafter referred to as cataract surgeons. Of these, approximately half reported never recommending blue light-filtering IOLs to their patients. The remaining cataract surgeons nominated 
that they recommended theses lenses occasionally (16\%), sometimes (5\%), mostly $(13 \%)$ or always $(16 \%)$. Of cataract surgeons who did not recommend blue lightfiltering IOLS, 53\% gave the reason that these lenses were not clinically justified.

Of cataract surgeons who implanted blue light-filtering IOLs, the three most frequent reasons were to act as a general safety measure against blue light (58\%), that their preferred IOL was only available with a blue light filter (45\%), and/or that the patient was at risk of developing AMD (39\%). The most common sources of information and/or evidence used by cataract surgeons to guide their clinical decision-making regarding blue light filtering IOLs were research papers (81\%), conference presentation (58\%), and recommendations from colleagues (48\%) (Figure 1b).

Almost half of respondents considered advertisements for blue light-filtering products to not accurately represent the risks associated with blue light exposure (Figure $2 \mathrm{a}$ ), and $\sim 70 \%$ of respondents considered there to be low quality evidence supporting the benefit(s) of blue light-filtering IOLs on macular health (Figure $2 \mathrm{~b}$ ). In assessing practitioners' perceptions regarding potential adverse effects, one in three respondents considered these implants to have adverse effects on colour vision, followed by sleep quality (31\%), scotopic vision (18\%) and photopic vision (14\%), with the remainder nominating 'none of the above' (42\%).

Our results indicate that one in two Australian cataract surgery respondents recommend blue light-filtering IOLS, despite only $25 \%$ considering daily environmental light to cause retinal damage. This discrepancy may reflect, at least in part, that almost half of respondents reported their preferred IOL to only be available with a blue light filter, suggesting that recommending these devices does not necessarily relate to their blue light-filtering properties per se. Cognitive dissonance in clinical decision-making in this practice area was also evident. Despite $\sim 70 \%$ of respondents considering the evidence for blue light-filtering IOLs being protective to macular health to be low, the most frequent reason for prescribing 
these lenses was as a general safety measure against blue light. Together, these findings demonstrate that blue light-filtering IOLs may be commonly recommended by cataract surgeons in Australia, with respondents' knowledge and attitude towards these lenses being mostly consistent with the best-available research evidence. 


\section{REFERENCES}

1. Noell WK, Walker VS, Kang BS \& Berman S. Retinal damage by light in rats. Invest Ophthalmol 1966; 5: 450-73.

2. Ham WT Jr, Ruffolo JJ Jr, Mueller HA, Clarke AM \& Moon ME. Histologic analysis of photochemical lesions produced in rhesus retina by short-wavelength light. Invest Ophthalmol Vis Sci 1978; 17: 1029-35.

3. Downie LE, Busija L, Keller PR. Blue-light filtering intraocular lenses (IOLs) for protecting macular health. Cochrane Database Syst Rev. 2018 ;5: CD011977.

4. Downie LE, Wormald R, Evans J, et al. Analysis of a Systematic Review About Blue Light-Filtering Intraocular Lenses for Retinal Protection: Understanding the Limitations of the Evidence. J AMA Ophthalmol. 2019; 137: 694-697.

5. Singh S, Anderson AJ, Downie LE. Insights into Australian optometrists' knowledge and attitude towards prescribing blue light-blocking ophthalmic devices. Ophthalmic Physiol Opt. 2019; 39: 194-204. 


\section{FI GURE LEGENDS}

Figure 1: (a) Percentage of respondents who considered each source to emit 'clinically important' levels of blue light. LED, Light emitting diode light source; LCD, Light Crystal Display computer screen; E-reader, Electronic-reader; O-LED, Organic Light Emitting Diode light screen; CRT, Cathode Ray Tube. (b) Percentage of respondents who selected each source of information or evidence for guiding their clinical decision-making in relation to prescribing blue light-filtering IOLs.

Figure 2: (a) Percentage of respondents who selected each level of agreement in relation to the statement: 'Advertisements for blue light-filtering products provide an accurate representation of the risks associated with blue light exposure.' (b) Respondents' perceived quality of the evidence relating to the potential beneficial effect of blue light-filtering IOLs on macular health, relative to UV-only filtering IOLs. 
TABLE

Table 1: Participant demographic information

\section{Characteristic}

Gender $(n=72)$

Male

Female

Principal type of work $(n=72)$

Academia

Private (Independent practice)

Multi-speciality hospital

Refractive surgery clinic

Public hospital

Other

Major mode of practice $(n=72)$

General

$17(24)$

Subspecialist

Sub-speciality $(n=55)$

Cataract

Corneal and external eye disease

Corneal refractive surgery

Glaucoma

Medical retina

Neuro-ophthalmology

Ocular oncology

Oculoplastics

Paediatrics

Strabismus

Uveitis and inflammatory eye disease

Vitreo-retinal

Other
$53(74)$

19 (26)
(\%)

Number of responses

\section{Years of ophthalmology}

experience $(n=72)$ 
$0-10$ years

11-20 years

21-30 years

$>31$ years
8 (11)

25 (35)

19 (26)

$20(28)$

This article is protected by copyright. All rights reserved. 

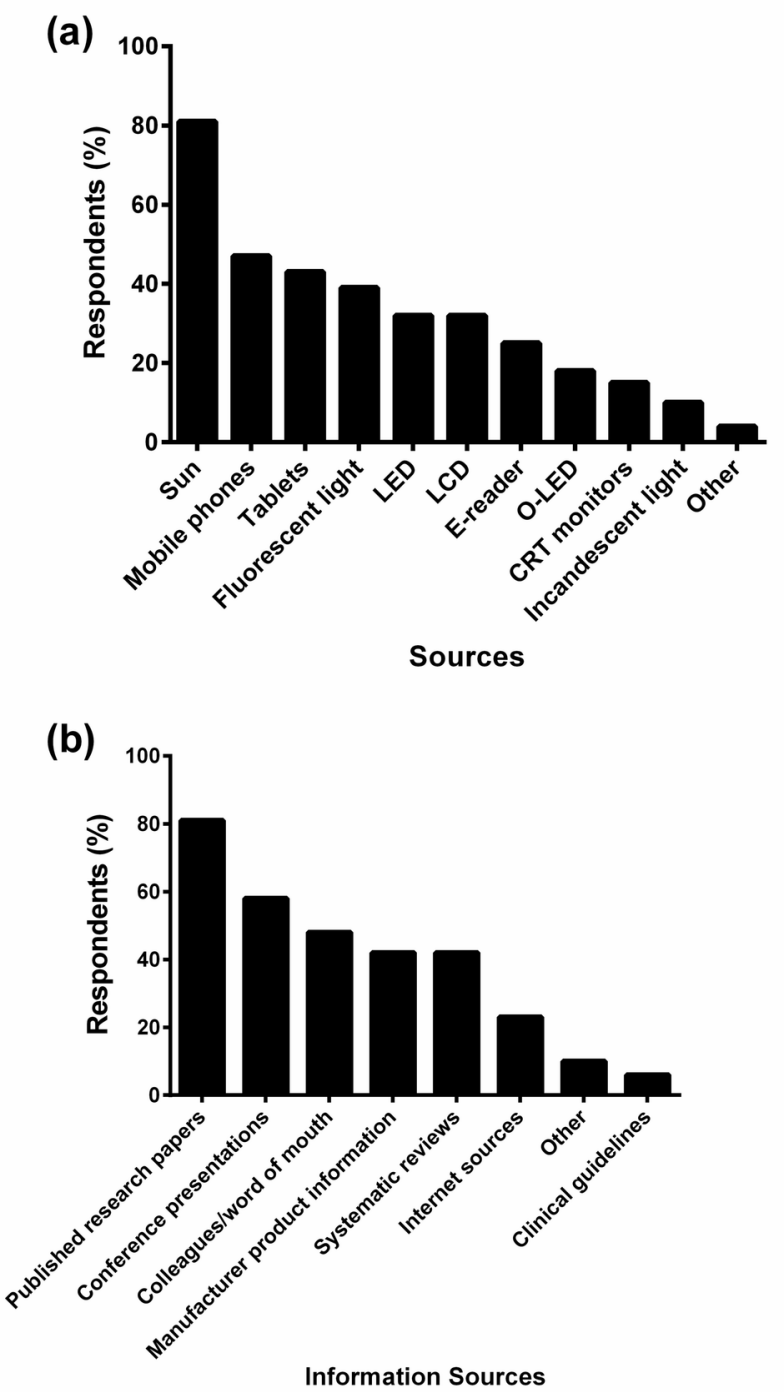

CE0_13653_Figure 1A and B.tif 

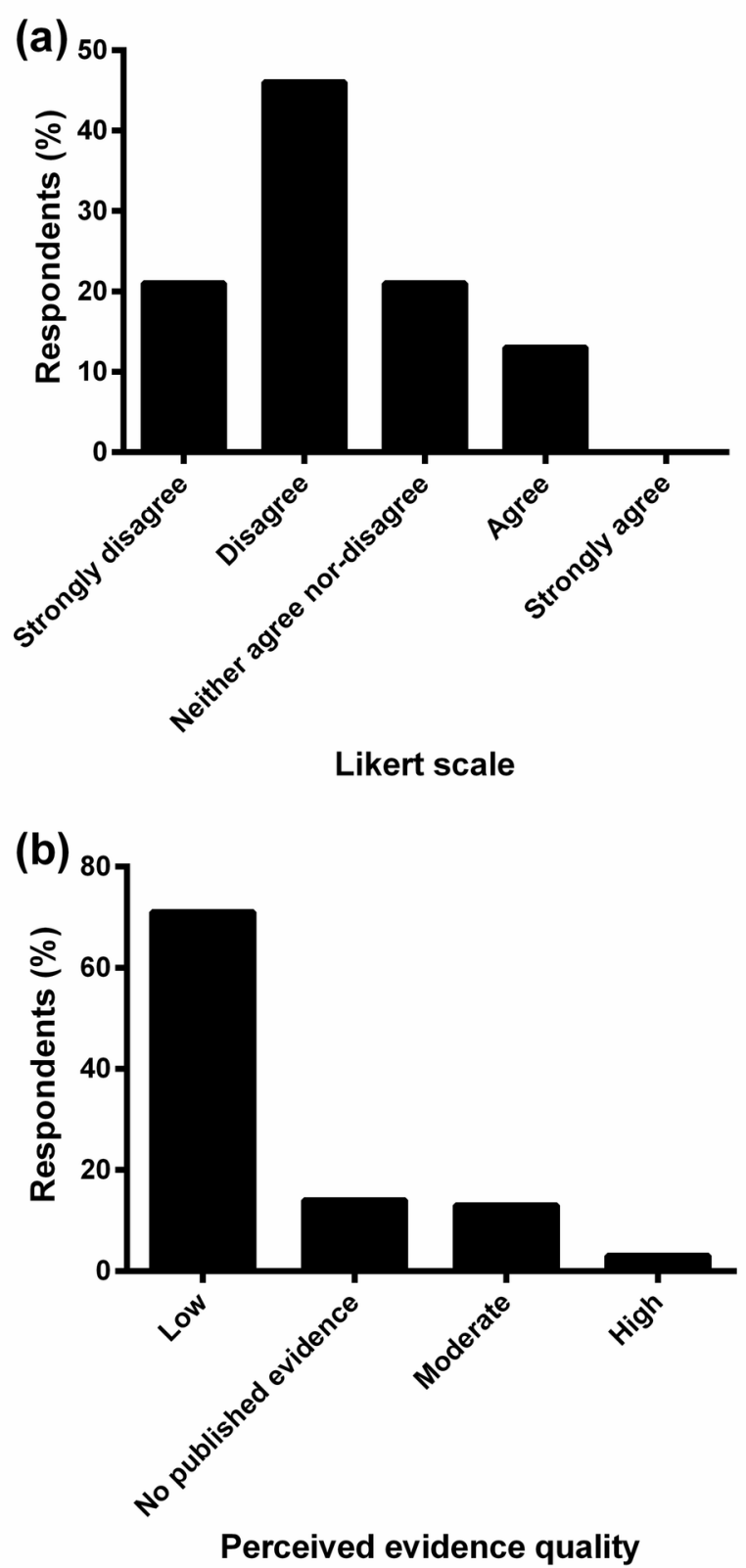

CE0_13653_Figure 2A and B.tif 


\section{University Library}

\section{- M M N E R VA A gateway to Melbourne's research publications}

Minerva Access is the Institutional Repository of The University of Melbourne

Author/s:

Singh, S;Anderson, AJ;Franzco, SLW;Downie, LE

Title:

Are current ophthalmology clinical practices relating to blue light-filtering intraocular lenses evidence-based?

Date:

2019-10-22

Citation:

Singh, S., Anderson, A. J., Franzco, S. L. W. \& Downie, L. E. (2019). Are current ophthalmology clinical practices relating to blue light-filtering intraocular lenses evidencebased?. CLINICAL AND EXPERIMENTAL OPHTHALMOLOGY, 48 (1), pp.125-127. https:// doi.org/10.1111/ceo.13653.

Persistent Link:

http://hdl.handle.net/11343/286530 